\title{
Millennials, Technology, and Cross-Cultural Communication
}

\author{
Antonina A. Bauman \\ Emporia State University \\ Nina V. Shcherbina \\ Pacific National University
}

New technologies, globalization and changing organizational cultures affect cross-cultural communication. The role of cross-cultural communications in success of business operations increased significantly over the last decade. Companies are looking for graduates with the skills that meet new business requirements. However, employers experience difficulties hiring new graduates as students demonstrate lack of communication skills. This study is designed to explore Russian and American student perceptions of the business cross-cultural communication methods and to compare those perceptions with current business practices.

\section{INTRODUCTION}

With the increased importance of international business and growing number of multinational companies, the issue of cross-cultural communication has become critical as it impacts many managerial processes including planning and organizing activities, decision making, and public relations (Kesari et al., 2014; Okoro, 2013). Globalization of markets or flow of products, resources, and culture (Ariely, 2012) requires professionals to find ways to communicate effectively and efficiently (Holtbrügge et al., 2013). It was emphasized that among the diverse set of skills that the global -ready graduate should have are communication skills (Danielewicz-Betz \& Kawaguchi, 2014; Harvey \& Knight 1996).

Studies conducted over the past decade stressed the importance of training managers on cross-cultural communication competence. The purpose of business cross-cultural education is to prepare individuals for jobs in the international environment. The topic of what students perceive as modern cross-cultural communication is worth investigating in order to make conclusions whether students' perceptions are similar to employers' expectations and if necessary, suggest adjustments to academic curriculum and improve students' employability.

\section{THEORETICAL BACKGROUND}

\section{Changing Business Environment and the Need for Cross-cultural Communication}

Recent political changes in the countries around the world, economic cooperation and interdependencies, and information and communication technologies increased the degree of globalization as well as changed both labour markets and work environments (Arnett, 2002; Castells, 
2010; Thompson et al., 2016). Many organizations have transformed from domestic into multicultural as they operate in the international, multinational, global or transnational environment (Bartlett \& Beamish, 2014; Molinsky et al., 2012; Okoro, 2013). These changes increase the role of communication in the overall success of business (Anand, 2014) and emphasize the need for employees with cross-cultural communication skills (Safina \& Valeev, 2015).

As companies become global and outsource manufacturing, assembly, and delivery of products to international partners, they rely on the communication technologies that allow cross-cultural teams work together across time zones and geographical distances (Holtbrügge et al., 2013). Although communication devices such as phone and fax have existed for decades, the Internet and especially the introduction of Web 2.0 in 2004 made a breakthrough with the interactive tools. Web 2.0 describes a set of technologies allowing people to create content on the Internet rather than on their desktops (O'Reilly, 2005). The most significant changes in the workplace are caused by technological tools, such as blogging and wikis, video and audio conferencing, which employees use to virtually work together either synchronously (at the same time) or asynchronously (with the delay in response time) as their schedules allow (Deal et al., 2010).

Today an employee, based almost anywhere, can have the means to complete all job requirements while having access to the Internet. There is no longer an "away from my desk" scenario; your desk can travel with you wherever you go (Ouye, 2011). This transformation of communication was noted as one of the most significant changes in the work environment (Castells, 2010).

\section{Business Communication Competencies}

As the accelerating pace of globalization makes companies think in terms of worldwide and not domestic operations (Thompson et al., 2016), the role of communication between business employees, their customers and suppliers becomes crucial. Communication skills emerge as among the most important employees' qualifications (Harvey \& Knight, 1996).

Communication skills are defined as skills that are 'mainly concerned with sending messages or transforming information clearly and receiving the message correctly' (Askary \& Qayyum, 2014, p.17). Business cross-cultural communication refers to the process of communication that crosses national boundaries for business purposes' (Guang \& Trotter, 2012, p.6457).

Beyond four basic communication skills of speaking, listening, writing, and reading (Askary \& Qayyum, 2014), communication researchers identified other competencies within business communication (Waldeck et al., 2012): relationship and interpersonal communication, mediated communication, inter-group communication, ability to communicate enthusiasm, and non-verbal communication.

\section{Millennials as a Workforce}

Millennials are people born between 1980 and 2000 (Gibson \& Sodeman, 2014; Howe \& Strauss, 2000; Smith \& Nichols, 2015) who started entering the job market of the 21 st century. As noted by many researchers, this is the first generation that was born into households with computers (Howe \& Strauss, 2000; Myers \& Sadaghiani, 2010). Hence, this generation is so comfortable with new technology that its representatives are referred to as 'digital natives' (Hershatter \& Epstein, 2010).

When it comes to work expectations, the most important thing for the Millennials is career advancement, quick promotion and salary increases. Next in importance is a nurturing work environment, good people to work with, and work-life balance (Ott et al., 2008; $\mathrm{Ng}$ et al., 2010).

Although the majority of trends exhibited by Millennials are considered by potential employers as positive contribution to their organizations (Howe \& Strauss, 2000; Myers \& Sadaghiani, 2010), researchers note some managerial challenges that organizations face while working with Millennials. One of those challenges is that Millennials seem to be self-focused and require more services and attention from the supervisors (Cahill \& Sedrak, 2012; Smith \& Nichols, 2015). For example, since Millennials are communicating using multiple electronic devices, they expect to receive responses to their inquiries instantaneously. This expectation of staying in contact extends not only to the Millennials' friends but 
also to their managers (Robinson \& Stubberud, 2012; Smith \& Nichols, 2015). Practitioners find Millennials to be in a need for constant feedback and assurance of their actions (Cahill \& Sedrak, 2012; Smith \& Nichols, 2015).

\section{PURPOSE}

Garima Bardia (2010) noted that the extensive use of the information technology, the growing role of the cross-cultural communication, and quicker communication are among the current communication trends. Our current generation of technologically savvy graduates is entering the workforce. However, employers are facing difficulties filling in positions. This study aimed at exploring perceptions of todays' students (who will become tomorrow's employees) about the use of technology in cross-cultural communication and comparing them with the employers' expectations.

\section{METHOD}

After careful consideration, a list of open-ended questions was compiled to collect the data. American and Russian university students were asked to participate in the study by answering survey questions listed below:

1. What is the most memorable experience you have had communicating with a person from a different culture?

2. Was it face-to-face or with the help of technology?

3. Did you ever use any technology in communicating with people from other culture(s)?

4. What type of technological or electronic device do you think is most useful for cross-cultural communication? Why?

5. If you had to communicate across cultures, what method of communication would you use? Would it be different from the answer in the previous question? Why?

6. When hiring for a job that requires cross-cultural communication, what skills do you think companies should require? Why?

7. When applying for a job that requires cross-cultural communication, what personal skills will you emphasize? Why?

Participants were encouraged to provide additional comments to better express their perceptions and opinions whenever it was possible. They did not receive any incentives to contribute to the study.

Surveys were distributed among students of management and cross-cultural communication courses and collected in two weeks. Eighteen American and seventeen Russian university students participated in this exploratory study. Table 1 lists basic demographic information about study participants.

TABLE 1

DEMOGRAPHIC INFORMATION ABOUT PARTICIPANTS OF THE STUDY

\begin{tabular}{|c|c|c|}
\hline Age group & Female participants & Male participants \\
\hline 18-20 years & 1 & 0 \\
\hline 21-24 years & 18 & 7 \\
\hline 25-29 years & 1 & 2 \\
\hline 30-34 years & 1 & 5 \\
\hline 35-39 years & 0 & 0 \\
\hline 40+ years & 0 & 0 \\
\hline Total & $\mathbf{2 1}$ & $\mathbf{1 4}$ \\
\hline
\end{tabular}


Respondents shared their personal experiences of cross-cultural communication and expressed their perceptions of what communication methods they would use in the workplace. Their answers were entered into an Excel spreadsheet for data processing and analysis. The key words for each answer were identified, tabulated, and analysed in accordance with the principles of the qualitative content analysis (Cooper \& Schindler, 2013; Schilling, 2006; Stemler, 2001). Two authors independently assigned categories and discussed results. After two rounds of categorization, the agreement rate reached acceptable level.

\section{RESULTS AND DISCUSSION OF FINDINGS}

All study participants had been in a situation that required cross-cultural communication. Most of the students had a face-to-face experience $(97 \%)$ with people from other cultures with the minority having online experience only (through the social media). It should be noted that $61 \%$ of American students said that they had to communicate with people from other cultures in the work environment, while $23 \%$ of Russian students had such experience. Over half of Russian participants $(63 \%)$ had to communicate while traveling (5\% of American participants did that). Other situations involving cross-cultural communication involved studying or participating in sports events.

In terms of the mode of cross-cultural communication, $72 \%$ of American and $88 \%$ of Russian students used technology in cross-cultural communication.

The results of the respondents' answer to the question 'What type of technological or electronic device do you think is most useful for cross-cultural communication?' are shown in the Table 2 below.

Almost a third of American students (27.8\%) and $41.2 \%$ of Russian students identified a smartphone as the most useful type of technology for cross-cultural communication. Popularity of this device can be explained by a nature of a smartphone as it combines several features which students find helpful: mobility and applications that perform a variety of tasks - from translation to the list of cultural customs to video conferencing. This result was somewhat expected as participating students represent the generation of Millennials (born between 1981-2000) who have been 'greatly shaped by the technological advances present during their childhood, college career, and into the workplace' (Gibson \& Sodeman, 2014:66).

Use of IT in communication is growing and different types of technologies are 'becoming extremely popular in the corporate circles nowadays' (Bardia, 2010, p. 31). However, among the variety of communication tools available (e-mail, Skype, blogs, audio and video conferencing online, wikis, and Twitter to name a few), e-mail is recognized as the most frequently used method by businesses (Holtbrügge et al., 2013; NCW Report, 2004). Here is the gap between what students listed as the top tool (smartphone) and what businesses actually use (e-mail) started emerging. Russian students did not mention e-mail as a useful way to communicate and $11 \%$ of American students listed e-mail as a useful technological tool. One has to keep in mind, however, that Russian students listed the Internet as the technological tool that can be used in different ways including sending messages either through the instant messaging or e-mail. 


\section{TABLE 2}

\section{STUDENTS' PERCEPTION OF USEFUL COMMUNICATION TECHNOLOGY}

\begin{tabular}{|l|r|r|r|r|}
\hline Type of technology & \multicolumn{2}{|c|}{ USA } & \multicolumn{2}{|c|}{ Russia } \\
\hline Video conferencing & 4 & $22.2 \%$ & & $0.0 \%$ \\
\hline Cell/Smartphone & 5 & $27.8 \%$ & 7 & $41.2 \%$ \\
\hline Computer & 3 & $16.7 \%$ & 2 & $11.8 \%$ \\
\hline E-Mail & 2 & $11.1 \%$ & & $0.0 \%$ \\
\hline Skype & 1 & $5.6 \%$ & 3 & $17.6 \%$ \\
\hline F2F & 1 & $5.6 \%$ & & $0.0 \%$ \\
\hline Social media & 1 & $5.6 \%$ & & $0.0 \%$ \\
\hline Pictures & 1 & $5.6 \%$ & & $0.0 \%$ \\
\hline Internet & & & 5 & $29.4 \%$ \\
\hline & 18 & $100.0 \%$ & 17 & $100.0 \%$ \\
\hline
\end{tabular}

Only one American student thought that face-to-face communication without the use of technology is the most useful way to get the message across. Some other unexpected option was the use of pictures. It would appear that the respondent who suggested it was referring to basic personal daily survival crosscultural communication than a business situation.

The third option that was identified only by one student was 'Social Media':

'The networking site Facebook. Facebook is the most useful for cross-cultural communication because it accommodates different time zones and sees if the person from the other side is on the other line. Also, it becomes difficult to communicate with people who are outside of the United States and the phone receptions are different.' (American student LT)

Table 3 shows the results of the content analysis of the answers submitted to the question: 'If you had to communicate across cultures, what method of communication would you use?

TABLE 3

\section{STUDENTS' PREFERRED METHOD OF CROSS-CULTURAL COMMUNICATION}

\begin{tabular}{|l|c|c|c|c|}
\hline & \multicolumn{2}{|c|}{ USA } & \multicolumn{2}{c|}{ Russia } \\
\hline F2F or Interpreter & 4 & $22.2 \%$ & 11 & $64.7 \%$ \\
\hline Skype video & 4 & $22.2 \%$ & 2 & $11.8 \%$ \\
\hline Smartphones & 2 & $11.1 \%$ & 2 & $11.8 \%$ \\
\hline E-Mail & 2 & $11.1 \%$ & & $0.0 \%$ \\
\hline Electronic translator & 2 & $11.1 \%$ & & $0.0 \%$ \\
\hline Computer & 2 & $11.1 \%$ & & $0.0 \%$ \\
\hline Social Media & 1 & $5.6 \%$ & & $0.0 \%$ \\
\hline Depends on a culture & 1 & $5.6 \%$ & 1 & $5.9 \%$ \\
\hline Internet & & & 1 & $5.9 \%$ \\
\hline Total & 18 & $100.0 \%$ & 17 & $100.0 \%$ \\
\hline
\end{tabular}


A somewhat surprising result was to see that when it came to selecting a type of technology for crosscultural communication, $64.7 \%$ of Russian students (compared to $22.2 \%$ of American) prefer to have face-to-face meetings despite the usefulness of the technological devices. The following comments were used to justify the choice of the face-to-face communication:

- 'I would use face-to-face communication because I could speak directly, to look at person's eyes, to see the reaction on communication, to clarify some misunderstandings if they would appear immediately. Also we may pay attention to the non-verbal communication on this case, for example, when people speak, their bodies may sometimes say different things than their words convey'[sic] (Russian respondent BR).

- 'The way I see it is that face-to-face communication is the best method to communicatem because it is easier to analyze a situation, when you can see your partner - you can see his or her reaction, get immediate feedback, non-verbal communication and so on' [sic] (Russian respondent GO).

- 'If I had to communicate across cultures, I would use face-to-face communication, my own extemporization and try not to lose the presence of mind' [sic] (Russian respondent KON).

- 'If I had to communicate across cultures the method of communication that I would use would be to spend a lot of time with people from the culture and learn directly from them' (American respondent $\mathrm{EW}$ )

- 'Face to face Verbal method of communication is always the most prevalent. You are less likely to miss-communicate through a misunderstanding because although your words may not be clear your body language and hand gestures can really make up the difference' [sic] (American respondent RR).

These statements show that first, students from both countries understand that as a concept, crosscultural communication involves both verbal and non-verbal exchange (McLean \& Lewis, 2010) and, second, they do appreciate and see the value of the dual nature of cross-cultural communication.

Video conferencing tool in general and Skype in particular took the second place on the list of the tools that students perceived to be useful in cross-cultural communication. The Skype video conference was selected by $22.2 \%$ of American students and by $11.8 \%$ of Russian students. Some of the students' comments are:

- $\quad$ 'Specific program named "Skype" - best way to speak with anyone, who's far away from you". If you can do smth, why doing this the hard way [sic] (Russian respondent ZA).

- 'If I don't have an opportunity to communicate face-to face, I'd rather use Skype because you can see people while talking to them. It allows to observe your companion's reaction, emotions right on the spot. It's more like face-to-face communication' [sic] (Russian respondent KH).

- 'May be Skype. You can see a person and it looks more like real talk' [sic] (American respondent $\mathrm{KM})$

- 'if you make friendship with somebody, belonged to another culture, you can talk to him on Skype, and get much information about representative of particular culture, it's not only what he is talking about, but also his mode of behaviour' (Russian respondent SHU).

- 'video conferencing will help people see each other's body language and tone' (American respondent MF)

- 'I find video chat to be useful as it allows a visual interaction that makes it easier to address any possible communication' (American respondent MM) 
- 'I think Skype, FaceTime or any type of video chat is the most useful for cross-cultural communication because it gives each individual the ability to see how the other person is acting while speaking. Even though the cultures may be different, as well as languages, body language through video chat can assist in any confusion of interpretation' (American respondent PK)

Comments about the use of smartphones for cross-cultural communication were about the tools and applications which are always at hand. Students noted a variety of options: from the video conference features like Skype to applications that help with the translation or finding information about cultural traditions and taboos for a specific culture.

- 'smartphone is the most useful device because it is alway at hand' [sic] (Russian respondent AF)

- 'I would choose sending mails with the help of mobile phone. Messages can be short and informative and in this case you needn't write long sentences with lots of formality. That's why you're out of the risk to make a horrible mistake. And I think even if you do it people wouldn't take it into consideration' [sic] (Russian respondent $\mathrm{SH}$ )

- 'Smartphones with internet because they are easily available and can help with any situation' (American respondent DLM)

- 'I can always use a mobile search app for information, even about the most frequent misunderstandings between my culture and the culture of the other person' (American respondent JM)

The common theme in student comments about video conference and a smartphone as their preferred method of cross-cultural communication is that this technology brings communication as close to the real face-to-face communication as possible.

Three options with the lowest scores were 'Social media', 'Depends on a culture', and 'Internet'.

When asked about what skills companies should require of employees $28.6 \%$ of American and $29.4 \%$ of Russian students listed foreign language and $21.4 \%$ of American and $29.4 \%$ of Russian students named tolerance towards people with different cultural backgrounds.

Overall, this finding is in line with the Daniel et al. (2014). In the Daniel et al. (2014) study, researchers surveyed 836 U.S. executives who had supervisory duties or were involved in HR decisions. They found that 'almost $85 \%$ of the firms will place a greater emphasis on international competence among management and employees over the next ten years' (Daniel et al,. 2014, p.28)

The fact that the 'writing skills' requirement was not listed by any student, shows a gap between what American businesses are looking for and what students' perceptions are. The National Commission on Writing for America's Families, School, and Colleges published a report in 2004 that presented results of the survey of major American corporations who employ nearly four million people. One of the findings was that 'eighty percent or more of the companies in the service and finance, insurance, and real estate (FIRE) sectors, the corporations with the greatest employment growth potential, assess writing during hiring' (NCW Report, 2004:3).

Later, in 2006, four American organizations (The Conference Board, Corporate Voices for Working Families, Partnership for 21st Century Skills, and the Society for Human Resource Management) surveyed 431 American employers, representing a combined workforce of over two million people, regarding the skills that new entrants into the workforce should have to be successful. They reported that $71.5 \%$ of employers considered written communication skills as "very important for two-year college graduates while $93.1 \%$ of employers said that these skills are very important for four-year college graduates (Casner-Lotto \& Barrington, 2006). Yet, 47.3\% of employers noted that two-year college graduates were found deficient ('lacking or poorly prepared') in these skills while $27.8 \%$ rated four-year college graduates as deficient (Casner-Lotto \& Barrington, 2006).

It is disturbing to see that even while contributing to the study of cross-cultural communication students do not think about the job requirement of having writing skills. It appears that students seem to 
differentiate between more generic communication skills and specific writing skills. The findings of this study show that while considering the use of technology in cross-cultural communication, more students think about oral communication rather than a combination of speaking, writing, and listening.

The last question was 'Which skills will you emphasize? Why?' showed that 26.75 of the Russian students will emphasize tolerance while $20 \%$ of American students - communication skills. An interesting observation is to compare what skills students list as qualifications for a job that involves cross-cultural communication and skills that they say that they would emphasize while applying for such a position.

- 'I would want to emphasize that I am fully capable of effectively communicating no matter what the communication barriers are' (American student HS).

For example, one American student listed communication skills as a job requirement but listening as the skill that should be emphasized: 'Although communication skills are important as a whole, it is important to listen to another's verbal communication, body language, and tone to understand how the person is taking to your cultural tendencies' (American student OS)

Emphasizing people skills rather than technical skills seems to be another trend among the students. People skills are 'the interpersonal attributes that characterize a person's relationships with others' (Robles, 2012, p. 457). Tolerance, cultural awareness, language and previous international experience are on the top of the list. Flexibility while dealing with other people, acceptance of and respect for other cultures are commonly used traits of character in the 'Tolerance' category, for example.

None of the students noted their ability to use technology to communicate across cultures, which presents a discrepancy between what students perceive is the most useful cross-cultural method of communication (Video conferencing and smartphone applications), what they list as a requirement for a job (foreign language skills and tolerance), and what skills they will emphasize when applying for a job (communication and tolerance).

A possible explanation to this finding could be that this generation of students takes their ability to use technology for granted as they were born during the Internet era. This is supported by Jill CasnerLotto and Linda Barrington (2006) who reported that two-year college graduates demonstrate $25.7 \%$ excellence in the application of information technology, while four-year college graduates were rated at $46.3 \%$ excellence in application of information technology.

This study confirms that the gap between what businesses use for cross-cultural communication and what students perceive is an important communication tool still exists and it is not getting any smaller. It is time to help both students and businesses to utilize current technology more effectively. For example, courses on managing social media should focus on the business use of social media while employees develop an understanding of the possibilities and skills that are needed to update their communication methods (Wankel, 2016).

Cross-cultural communication trends reflect technological developments in communication and establish new communication preferences based on a combination of cultural values and increased collaboration (Castaneda \& Bateh, 2013). As the role of cross-cultural communication is crucial for success of businesses (Barrett, 2014), it is important to convey these changes to students, in order to prepare new business leaders for multi-cultural work environments.

\section{LIMITATIONS AND IMPLICATIONS}

This study, as any research, has its limitations that should be mentioned. First, this was an attempt to explore students' perceptions of the use of different methods of cross-cultural communication. The sample size was relatively small - thirty five qualitative structured surveys were obtained and answers to the open-ended questions were analysed. One should be cautious about drawing conclusions and generalizing findings. 
Another limitation of this study is that respondents were students majoring in business and studying cultural differences. However, businesses hire students majoring in other subjects, and it would be interesting to analyse their perceptions of cross-cultural communication.

As the result of the content analysis, several observations were made about a gap between employers' and students' views on workforce skills in the area of cross-cultural communication. This study supports earlier recommendations (Gibbs et al., 2011) for better communication between businesses and educational institutions regarding overall students' skills needed in the workplace and cross-cultural communication skills in particular. The gap between what business employers define as important skills and students perceptions about those skills should be minimized. The course curriculum for cross-cultural communication should be regularly updated to reflect changing needs of the business world. Although it is unrealistic to expect that the gap will be completely eliminated as students' perceptions of job requirements and employer's expectations will always be different, it is realistic to expect that some basic cross-cultural communication skills could be developed during the students' course of study.

This paper offers support for making curriculum changes and adjustments to content of the business communication courses in order to eliminate the gap between students' perceptions and the business community requirements and expectations of cross-cultural communication skills developed by students while there are studying in universities.

\section{CONCLUSION}

With the globalization expanding, the cross-cultural communications is one of the major issues for international companies (Kesari et al., 2014; Okoro, 2013). To be successful in the competitive market, one has to master cross-cultural communication (Anand, 2014; Guang \& Trotter, 2012).

Companies notice that, on the one hand, current business trends of globalization, diverse workforce, team-based organizations, advances in technology, and flatter organizational structure impact communication trends in the workplace (Bardia, 2010). On the other hand, technology is brought down to the level of the individual and the physical location of an employee often does not matter as employees become a part of the global network (Charles, 2011). Between globalization and technology 'modern business communication has become a diverse, dynamic field which has increased its relevance and significance than ever before'(Bardia, 2010, p. 31).

As Mirjaliisa Charles (2011) stated, an older approach to communication as 'communication in business' is changing to become a 'communication is business' paradigm (Charles, 2011, p. 31) that should be the focus of a business strategy. More and more businesses recognize it and expect new workforce to be able to communicate in clear and effective way. To meet these expectations, academic institutions aim at preparing future employees who can perform to the best of their abilities (Daniel et al., 2014). As our current students will be entering the workforce that has to deal with the diversity of peers and customers, they will have to learn how to match job requirements with the available technology and their personal skills.

\section{REFERENCES}

Anand, P.K. (2014). Cross Cultural Diversity in Today's Globalized Era. Journal of Human Resource Management, 2(6-1), 12-16.

Ariely, G. (2012). Globalisation and the decline of national identity? An exploration across sixty-three countries. Nations and Nationalism, 18 (3), 461-482.

Arnett, J. (2002). The Psychology of Globalization. American Psychologist, 57(10), 774-783.

Askary, S. \& Qayyum, M.N. (2014). Communication Skills, Cultural Changes, and Intellectual Capital:

A Theoretical Framework. Global Journal of Human-Social Science Research, 14 (1),16-24.

Bardia, G. (2010). Smart Communication: The Key to Managing Your New Age Business. The IUP Journal of Soft Skills, 4(4), 27-33.

Barrett, D. (2006). Leadership communication, New York: McGraw Hill Irwin. 
Bartlett, C.A., \& Beamish, P.W. (2014), Transnational Management: Text, Cases and Readings in CrossBorder Management, $7^{\text {th }}$ edition, New York: McGraw Hill Irwin.

Cahill, T.F. \& Sedrak, M. (2012). Leading a multigenerational workforce: Strategies for attracting and retaining millennials. Frontiers of Health Services Management, 29(1), 3-15.

Castaneda, M.E., \& Bateh, J. (2013). Strategies for multicultural management: communication and a common set of values. Journal of International Education Research, 9(1), 41- 46.

Castells, M. (2010), The rise of the network society: The information age: Economy, society, and culture, $3^{\text {rd }}$ ed, Chichester: Wiley-Blackwell, John Wiley \&Sons.

Charles, M. (2011). Business communication: Mapping a road for the future. Synaps: A Journal of Professional Communication, 26, 25-33.

Cooper, D., \& Schindler, P. (2013). Business Research Methods, $12^{\text {th }}$ ed., New York: McGraw Hill/Irwin.

Danielewicz-Betz, A. \& Kawaguchi, T. (2014). Preparing Engineering Students for Global Workplace Communication: Changing the Japanese Mindsets. iJEP, 4(1), 55-68.

Deal, J.J., Altman, D.G., \& Rogelberg, S.G. (2010). Millennials at work: What we know and what we need to do (if anything). Journal of Business and Psychology, 25(2), 191-199.

Gibson, L.A., \& Sodeman, W.A. (2014). Millennials and Technology: Addressing the Communication Gap in Education and Practice. Organization Development Journal, 32(4), 63-75.

Guang, T., \& Trotter, D. (2012). Key issues in cross-cultural business communication: Anthropological approaches to international business. African Journal of Business Management, 6(22), 64566464.

Harvey, L. \& Knight, P.T. (1996). Transforming Higher Education. Bristol, PA: Open University Press, Taylor \& Francis.

Hershatter, A. \& Epstein, M. (2010). Millennials and the world of work: An organization and management perspective. Journal of Business and Psychology, 25(2), 211-223.

Holtbrügge, D., Weldon, A. \& Rogers, H. (2013). Cultural determinants of email communication styles. International Journal of Cross Cultural Management, 13(1), 89-110.

Howe, N. \& Strauss, W. (2000). Millennials rising: The next great generation, New York: Vintage.

Kesari, B., Soni, R. \& Khanuja, R.S. (2014). A review on the need of cross cultural management in multinational corporations, International Journal of Advanced Research in Management and Social Sciences, 3(8), 120-127.

Klobucher, T. (2011). Characteristics of generation 2020: Generations at work, http://www.thegreatworkplacerevolution.com/characteristics-of-generation-2020-generations-atwork/ (accessed 2015, January 27).

Molinsky, A.L., Davenport, T.H., Iyer, B., \& Davidson, C. (2012). Three Skills Every 21st-Century Manager Needs. Harvard Business Review, 90(1-2), 139-143.

Myers, K.K., \& Sadaghiani, K. (2010). Millennials in the workplace: A communication perspective on millennials' organizational relationships and performance. Journal of Business and Psychology 25(2), 225-238.

Ng, E.S., Schweitzer, L., \& Lyons, S.T. (2010). New generation, great expectations: A field study of the millennial generation. Journal of Business and Psychology 25(2), 281-292.

Okoro, E. (2013). International Organizations and Operations: An Analysis of Cross-Cultural Communication Effectiveness and Management Orientation, Journal of Business \& Management (COES\&RJ-JBM), 1(1), 1-13.

O'Reilly, T. (2005). What Is Web 2.0? Design Patterns and Business Models for the Next

Generation of Software, http://oreilly.com/web2/archive/what-is-web-20.html (accessed 25 April, 2017).

Ott, B., Blacksmith, N., \& Royal, N. (2008, March 13). What generation gap? Business Journal, Gallup, http://www.gallup.com/businessjournal/104845/Something-Generations-Can-

Agree.aspx?g_source $=\mathrm{Job} \% 20$ seekers $\% 20$ for $\% 20$ different $\% 20$ generations $\% 20$ often $\% 20100 k \% 2$ 0 f\&g_medium $=$ search $\& g$ _campaign $=$ tiles (accessed 25 April 2017).

Ouye, J.A. (2011). Five trends that are dramatically changing work and the workplace, http://www.knoll.com/research/downloads/WP FiveTrends.pdf (accessed 22 February 2016). 
Robinson, S. \& Stubberud, H.A. (2012), Millennial Workforce: Communicating And Multitasking. International Journal of Management \& Information Systems (IJMIS), 16(4), 307-316.

Safina, M. S. \& Valeev, A.A. (2015). Study of Humanitarian High School Students' Readiness for Intercultural Communication Formation, Review of European Studies, 7(5), 52-60.

Schilling, J. (2006). On the pragmatics of qualitative assessment, European Journal of Psychological Assessment, 22(1), 28-37.

Smith, T. J. \& Nichols, T. (2015). Understanding the Millennial Generation. The Journal of Business Diversity, 15(1), 39-47.

Stemler, S. (2001). An overview of content analysis. Practical Assessment, Research \& Evaluation, 7(17), 137-146.

Thompson, A., Peteraf, M., Gamble, J., \& Strickland, A.J. (2016). Crafting \& Executing Strategy $20^{\text {th }}$ ed: The Quest for Competitive Advantage: Concepts and Cases, New York: McGraw-Hill Education.

Waldeck, J., Durante, C., Helmuth, B., \& Marcia, B. (2012). Communication in a changing world: Contemporary perspectives on business communication competence. Journal of Education for Business, 87(4), 230-240.

Wankel, C. (2016). Developing cross-cultural managerial skills through social media. Journal of Organizational Change Management, 29(1), 116-124. 